\title{
Safety regulation: the lessons of workplace safety rule management for managing the regulatory burden
}

Andrew Hale ${ }^{1}$, David Borys ${ }^{2}$, \& Mark Adams ${ }^{3}$

1. Chairman HASTAM, UK \& Emeritus Professor, Delft University of Technology, Safety Science Group, Netherlands

2. Senior Lecturer, Victorian Institute of Occupational Safety \& Health, Ballarat University, Victoria, Australia

3. Mercatus Center, George Mason University, Arlington, Virginia, USA

\section{Abstract}

There is a strong political consensus in a number of countries that occupational safety and health regulation is stifling industrial innovation and development and is feeding a culture of damaging risk aversion and petty bureaucracy. In a number of countries this has led to proposals to repeal regulations and reduce the regulatory burden. The authors were commissioned to prepare a discussion paper on this issue by the Mercatus Center of George Mason University in Arlington, Virginia, aimed particularly at an American audience.

The paper is based on previous work of the first two authors, developing a framework of safety rule management at the workplace level (Hale \& Borys 2012a and b). Based on a literature study, this paper analyses the similarities and differences between rules at the workplace level and the development, use and enforcement of regulations at the national level to influence and control organisational behaviour. It traces the forces encouraging the growth of regulatory detail and hence the bureaucratic burden of compliance and the options open to reduce that burden without loosening control so much that the level of safety declines. The analysis uses the hierarchy of rules from goals, through process (risk management) rules to detailed action rules as framework for predicting the level of ownership and responsibility felt by the regulated.

\section{Introduction}

In many countries there have been complaints of the burden imposed by laws and regulations on industry, particularly where those regulations have been of a detailed and prescriptive nature. The following quotes give a flavour of them:

"The first and most fundamental defect...is simply that there is too much law."

(Lord Robens, 1972)

"Government regulations impose an enormous burden on large and small businesses in America, discourage productivity, and contribute substantially to our current economic woes."

(Ronald Reagan, 1981)

"We are seeking more affordable, less intrusive means to achieve the same ends - giving careful consideration to benefits and costs. This means writing rules with more input from experts, businesses, and ordinary citizens. It means using disclosure as a tool to inform consumers of their choices, rather than restricting those choices.

(Barack Obama, 2011)

In 2011 the USA businesses were required to comply with 165,000 pages of regulations, covering all areas, not just safety. A goal of presidents at least since Lyndon Johnson and continued under Gerald Ford and Richard Nixon has been to reduce the burden of regulation. This effort was expanded during the Carter administration with the elimination of two major regulatory agencies and the creation of the Commission on Price and Wage Stability, which examined the contribution of regulations to the inflation problem. Out of that Commission the Reagan administration created the Office of Information and Regulatory Affairs (OIRA) to conduct economic analysis of all major regulations created by the executive agencies (but not of independent agencies). 
Presidents Clinton and Obama have both reaffirmed the government's commitment to reducing the burden of regulation, yet despite broad bipartisan support for ensuring that the benefits of regulation justify their costs, the scale of the regulatory burden has not lessened. Instead the number of pages in the Code of Federal Regulation, and the cost imposed by regulation, has increased under every president (Dudley et al 2010).

There have been two reports in the UK in the last two years one of whose objectives has been to examine whether regulations could be repealed, reduced in size or simplified (Lord Young 2010, Löfstedt 2011). Although their recommendations include proposals for some repeals, these are largely of old, forgotten regulations and have not included major reductions in the burden. The Netherlands has gone further in recent years and has set in motion a major revamping of the law by delegating the writing of rules (called Arbocatalogi or Working Conditions Catalogues) to sector parties (employers federations, trades unions, professional bodies), with the promise that, once these are approved and in place, the detailed government regulations will be largely repealed (Baart \& Raaijmakers 2010, Heijink \& Oomens 2011). However, even this major shift in responsibilities may not tackle the issue of the quantity of regulations.

One company level study in Australia received submissions from companies indicating that $25 \%$ of senior managers' time was spent on compliance (Australian Chamber of Commerce \& Industry, 2005).

In this paper, based on the report to Mercatus (Hale et al 2011), we will summarise some of the literature indicating the nature of the burden of safety regulations. It will use the distinction according to the style of rules, and the framework of rule management developed for the workplace level (Hale \& Borys, op cit.), and adapt those to the regulatory level to arrive at suggestions for improvements. These are often ones already applied in Europe and Australia, but are novel to the USA.

\section{Responding to new regulations}

When a government agency issues a new or modified regulation, companies must spend time discovering whether it applies to them and, if so, whether there is a gap between their current practices and those now mandated by the regulator. If there is no gap, the initial costs of the regulation are limited to this discovery cost (although there may be longer-term costs if the regulation locks in current production or risk-control methods and prevents them being superseded by more effective ones). If there is a gap, companies must determine what else they must do, or do differently, to comply with the new regulations. Compliance may impose costs associated with adopting new methods of production, retraining employees, or buying new materials and equipment. However, this compliance review also gives companies the opportunity to improve their processes so as to achieve gains in productivity or in quality or pollution control, and these improvements mitigate the overall cost of compliance. These activities consume the time and energy of managers and employees, who must devise and implement the assessments, changes, and notifications, and they divert human resources from other activities. Compliance costs fall disproportionately on small businesses, which lack the ranks of internal management for translating large and complex rules sets. Moreover, regulations are often written with a view to the complex and formal internal procedures of large companies and are ill-suited to implementation by smaller companies. This may put smaller but more flexible companies at a competitive disadvantage and discourage entry into markets by smaller companies. Large firms can absorb the cost of regulation more easily than small firms: there is a minimum amount of time needed to find, interpret, and apply a regulation no matter how small the business and these costs cannot be spread over so much productive time in a small firm as in a large one. Crain \& Crain (2010) arrived at a disproportionate cost per employee of 30-36\% over big companies. Small firms, which operate on informal communications, are saddled with bureaucratic systems and reporting requirements; regulations do not allow for less commonly occurring technical variations in regulated processes and so innovations in developing potentially beneficial technical variations are discouraged.

Compliance with detailed, prescriptive regulations may build a reactive compliance culture, which stifles innovation in developing new products, processes, and risk control measures. Regulators often respond more slowly than companies to changing market conditions, locking industry into outdated production methods. 
Additional costs come from the burden of record keeping and reporting to the regulator about compliance. These costs can reduce competition and increase prices for products and services. When every company is forced to adopt the same strategy in detail, it is harder to see whether another strategy would be more effective. Moreover, as each firm must comply with the same detailed rules, there is no competitive advantage for any firm that bears the cost of discovering and implementing more efficient rules. Saji (2003) mentions that there is often a long delay in certifying new equipment in strictly regulated processes. This discourages companies from adopting innovations that depend on yet uncertified equipment.

Against these costs must be set the benefits of the new regulations in terms of safety, health and environment.

\section{Dynamics of regulation}

There is a dynamic in regulations in which, if existing regulations are seen to fail, new ones are added to plug the gaps. Rules may also be made more specific and detailed to assist in enforcement (Robens 1972, Gunningham et al 1998, Gunningham \& Johnstone 1999, Jentoft \& Mikalsen 2004). As Howard (1994) laments:

"We have too easily succumbed to the siren song of regulation or rather... of comprehensive regulation. We are too easily moved by notions of rationalized completeness."

Banks (2006) describes this as a culture of "regulate first and ask questions later." Some scholars attribute this to regulatory risk-averseness, as regulators diligently seek to cover every eventuality and produce redundant rules (Beck 1992, Lord Young 2010). Regulatory risk-averseness is partially a consequence of the incentives facing regulators: they are more likely to be blamed for a failure to prevent a new problem than for excessive means to control an old problem. Olson (1982) observes that the number of lobbying associations representing companies and industries tends to increase markedly over time. He finds that industry groups lobby for beneficial rules and then other groups lobby for exceptions to those rules. Over time this leads to an accumulation of rules, which

"...increases the complexity of regulation, the role of government, and the complexity of understandings, and changes the direction of social evolution."

Indeed, work by Stigler (1971) and Peltzman (1976) found that a substantial majority of the economic regulation in effect in the 1970s benefited industry rather than consumers by shutting out competitors. The difficulty of changing rules at a regional or national level leads to ossification of the regulations and of the companies complying with them.

Detailed regulations are hard to understand because of their legalistic phrasing and complexity, and it is often difficult to determine whether a particular rule applies in a given situation (Loosmore \& Andonakis 2007). Companies complain of inconsistencies (Burman \& Daum 2009). The problem with jurisdictional boundaries is particularly salient when several agencies have overlapping authority over some areas of a company's activities, and especially when one agency's regulations conflict with another's, which happens most often when the regulations are detailed (Aagaard 2011).

When the only way to change the rules is to lobby the regulator to impose the change at national or regional level, the cost of changing rules becomes much higher because more stakeholders are involved. This, coupled with regulator risk-averseness reduces the benefits of innovation and favours a compliance-, rather than an innovation-culture. Centrally formulated regulations cannot easily reflect the diversity of situations to which they apply; provisions are therefore set for the majority of applications or in the interests of the firms that lobby the hardest. This leaves firms to struggle under sub-optimal regulation and with no easy way to handle exceptions to the norm. Firms also tend to have better information than the regulator about their own industry, certainly in respect of new technological and organizational advances (Australian Chambers of Commerce 2005). At the extreme, the regulations may be impossible to apply in some cases or may even create danger, because the regulator defining them has insufficient knowledge of practice. 
Studies show that imposed rules are seen as "not invented here" and to be complied with at best only in the letter and not the spirit, with the least possible commitment, if at all (Lord Robens, Lavérie \& Flandrin 1991). Detailed rules imposed from the outside discourage companies from studying their own risks and using their own expertise in their technology and organization to devise effective and efficient ways to control risk.(Ogus 2002, Jones \& Graf 2001, Majumdar \& Marcus 2001)

Companies lose the sense that they own the problem of managing the risks inherent in their business. This sense of loss of ownership is particularly evident in small companies: small companies faced with detailed rules tend to wait until an inspector visits and then to ask him exactly what should be done and to do that. They thus fail to determine for themselves what the best means of compliance would be (Fairman \& Yapp 2005). Brockner et al. (2004) characterize this mode of risk management as a reactive "prevention mode," which they unfavorably contrast with a creative and proactive "promotion mode."

This section has traced a number of negative effects of regulations imposed from outside, particularly if they are detailed and specific. We turn now to some general principles of rules and rule-making which place these issues in a framework to allow us to offer proposals for improvement.

\section{Concepts and frameworks}

Rules exist to influence behavior by specifying what the behavior should be or should achieve and applying some form of motivation to encourage it. That motivation may be complex, including some or all of the following: to do a good job, to conform to social expectations and pressures, to comply with the law, or to escape punishment. Rules about safety and health, which are our focus, may be aimed at the behaviour of workers, designers, managers, clients, contractors, visitors, local residents, or the public. We use the word "rule" very generally, as any routine or procedure that can be devised by anybody, including the person who carries out that behavior. Thus an employee manual, a set of best practices, and the working habits of an individual worker may all be considered rules under this broad definition. They may or may not have formal sanctions attached to non-compliance, and there will often be rewards socially, financially, or in effort and comfort in breaking the rule. There are very few "golden rules" that have no exceptions. Dealing with those exceptions is a key issue in rule management (Antonsen et al 2008, Dekker 2005, Leplat 1998). It can contribute greatly to the size and complexity of rule sets, as rules are extended to cover the exceptions, usually after an accident or incident not covered by any rule.

Regulations form a subset of rules. They are rules imposed by the executive or independent agencies with the force of law and an explicit threat of punishment for non-compliance. Our analysis of regulations also applies to some voluntary rules issued by organizations other than governments, such as insurers as well as standards and certification authorities. These differ from regulations in that companies can opt out if they judge that the rules are not appropriate to them. Some regulations issued by traditional regulators may share some features with voluntary rules, such as regulations that create defaults with opt-outs. The essence of regulations is that they are imposed by an external authority on an organization, group, or individual that must comply and are backed by some form of institutionalized sanction for non-compliance.

The level of generality at which rules are formulated significantly affects the size of any rule book or set of regulations (Hale \& Swuste 1998, Grote 2006). We divide generality into two aspects: how concrete the rules are, by which we mean how easily measurable the result is, and how restrictive is the rule to the freedom of discretion of the rule-follower on how to comply (Goals, risk management process rules and detailed action/state rules). We describe each of these in turn:

1. Goals. These are outcome-based rules specifying outcomes but not how to achieve them. The outcomes differ in how concrete and measureable they are. At one end of the spectrum they might specify, "this factory will release not more than 200 tons of mercury into the atmosphere each year." At the other end the goal may be vague: "drive safely," or "workplaces shall be designed to prevent injury or ill health, so far as is reasonably practicable." In the case of the abstract rules there is an 
extra translation process in defining precisely what such words mean. This translation into actual behavior is left to the discretion and competence of the person upon whom the regulation is imposed, although this may be guided by dialogue with the enforcement authority.

2. Risk-management process rules. These specify how to arrive at the required behavior, but not what that behavior is, for example, "conduct an effective risk assessment before starting any new work task and eliminate or control any risks found," or "submit a safety case for approval by the authority." All regulations requiring organizations to have a safety management system to control their risks fall under this heading as do safety case regimes requiring submission of a reasoned analysis of risks in a proposed activity and the means proposed to control them. There are few regulations for management systems in the United States. The OSHA Process Safety Management of Highly Hazardous Chemicals standard (29 CFR 1910.119) is an exception applying to major hazard companies. However, there are voluntary private sector rules issued by ISO, ANSI, and others on safety management, which may be used by companies to populate this category of rule. Companies in the United States may also pay attention to the management criteria incorporated in the criminal prosecution guidelines set by the Environmental Protection Agency, the Food and Drug Administration, and the Department of Justice, because a firm found in non-compliance with a regulation is more likely to be subject to criminal prosecution if the agency determines that noncompliance arises from a deficient management system. Design standards such as the European norm for machinery safety are also of this form (CEN 1992). As with rules that take the form of goals, there must be a translation process from the risk-management process rule to the specific behavior. This relies on the competence of the regulated organization to win the approval of a regulator. However, the room for interpretation is smaller than for translating a goal.

3. Action/state rules. These specify closely the behavior to be shown in a defined or implied situation, for example, "approved hard hats will be worn by all personnel within the bounds of the construction site," or they define the state to be achieved: "scaffolding will be close boarded and have toe-boards at least $\mathrm{x}$ inches high." Even here there is some leeway left for translation in terms of what is meant, in the first example, by "approved" (matching what standard? approved by whom?), "personnel" (employee, contractor, visitor?) and "construction site" (within what bounds, office as well as open site?), but this is now minimal. Action rules have the advantage that compliance can be measured without having to wait for the eventual outcome it is designed to control: a machine guard can be seen to be in place without waiting to see if an accident occurs. This gives the regulated more immediate certainty that they are in compliance.

There are a number of postulates, which have been derived in earlier studies of this classification system (Hale \& Swuste 1998, Hale \& Borys 2012a and b):

- The more that regulations are phrased as action rules, the more rules there must be to cover a given breadth of activities or risks. It is frequently regulations at this level that we hear complaints about as imposing a too great a regulatory burden. Many European countries and Australia have moved from action rules to goal-setting or risk-management process regulation, leaving the regulated to devise their own action rules, because of this concern about the proliferation rules. The United States has not followed this trend.

- The more rules are specified at the action level, the more exceptions there will be to which the rule does not, or cannot, apply. Following the rule may even be dangerous in some circumstances.

- Rules at the level of goals, outcomes, and risk-management processes are subject to fewer exceptions but give less certainty to companies of what to do or not to do and less guidance to the enforcer of what to approve and what to disallow.

- If the formulation of an outcome rule is not concretely measurable, the regulated have two translation processes to accomplish: what the rule means in practice and how to comply with it. Concrete outcome-based rules only impose the latter. 
- Serious accidents that are not the result of a breach of existing regulations are often portrayed in accident investigations as stemming from gaps or exceptions to the existing regulations or failures to interpret generic rules for the specific situation encountered. As such they tend to spawn new regulations, usually at an action-rule level, to outlaw the behavior that led to the accident. This increases the size and complexity of the rule set.

- If regulators do not impose action rules for an activity, it is up to the companies and persons carrying out that activity to translate safety goals into specific behavior. To do this, they must have time, motivation, competence, and authority.

- Unless a rule is imposed from above, the people facing the risk must formulate a rule for their own behavior at each moment. The question is not whether an action rule is needed but at what level in the hierarchy the action rule is formulated and on what levels it is imposed (i.e., how many actions become enshrined in regulations and how many stay as self-imposed rules).

- Imposing an action rule limits the freedom of choice of companies more than rules that specify goals or risk-management process rules, but this may also limit the level of competence needed to interpret the rule, provided that the action rules are appropriate to the situation the company is facing and are relatively simple to discover and understand.

- There is strong pressure to frame rules as action rules for situations in which there will be little decision time (for example, rules for emergencies). However, when workers are confronted with novel situations for which no action rules exist, or for which the rules are not applicable, field expertise will be valuable to devise appropriate ways of behaving to match those situations (Weick 1996).

- The more concern there is for creating a level playing field where all are subject to the same rules, the more there is pressure to specify rules in concrete ways that are easy to monitor and enforce. This will entail using fewer process rules and vague goals, which must be negotiated by companies, and more concrete goals or action rules.

- The more that many people must collaborate on an activity, the more pressure there is to specify action rules so as to increase the degree of certainty that specific behavior will be predictable for all concerned. For example, rules for which side of the road to drive are essential to make other drivers' behavior predictable.

- The more extensive the set of action rules imposed, the more likely it is that the individuals and organizations will work in compliance mode and the less willing they may be to invest in experts who can respond creatively to exceptional risks and their control.

- The more that the relationship between the company and the regulatory auditor or enforcer is antagonistic and not based on trust, the more there will be debate and conflict over the interpretation of the rules, and the more pressure there will be to define them at a specific action level, thus increasing their number and complexity. This is not to say that trust should be unquestioning, a situation that leads to private interests capturing regulators for their own benefit.

As we have described, there are many forces driving companies to adopt rules that define actions and become increasingly detailed and complex over time. On the other hand, competition and the pursuit of profit are countervailing forces on companies that encourage them to prefer to reduce rule sets or to make them more flexible for the sake of freedom of choice, efficiency, and innovation. We postulate that the same pressures to increase the size of rule sets apply to regulators, but regulators do not make profit from adopting more efficient rules nor are they subject to competitive pressures. Regulators may face lobbying efforts by firms to avoid onerous regulations, but firms may also support regulations that are harmful to their competitors.

There is a choice as to which level of rule to use when formulating regulations, and there is a correlation in moving up or down the continuum between the discretion and freedom of choice left to the company and the competence needed to translate the regulation into practice. Freedom of choice is linked closely to uncertainty. Regulatory uncertainty may arise in three ways: 
1. Uncertainty from vague and overbroad rules. Small firms may delay compliance until the regulator or the courts provide firm definitions in the form of action rules. Evidence shows that not only will firms delay making decisions when courts make unclear rulings, but regulators will also often stick with outdated procedures until courts hand down a clear decision (Baum 1976)

2. Uncertainty from excessively complex rules sets. Just as vague rules give firms little guidance, too large rule sets leave firms wondering about which rules apply to them.

3. Changing rules. Although it is necessary for rules to respond to changing circumstances, firms are less likely to comply if they believe that rules will change (Daugiradas 2005)

The flexibility of the rule and the uncertainty of the rule are related. Flexible rules are more likely to be vague if the regulator does not define specific outcomes. However, detailed rules are harder to discover and may lead to increased uncertainty over which rules apply to the firm. Furthermore, detailed rules must change more frequently to keep pace with innovation, creating additional uncertainty.

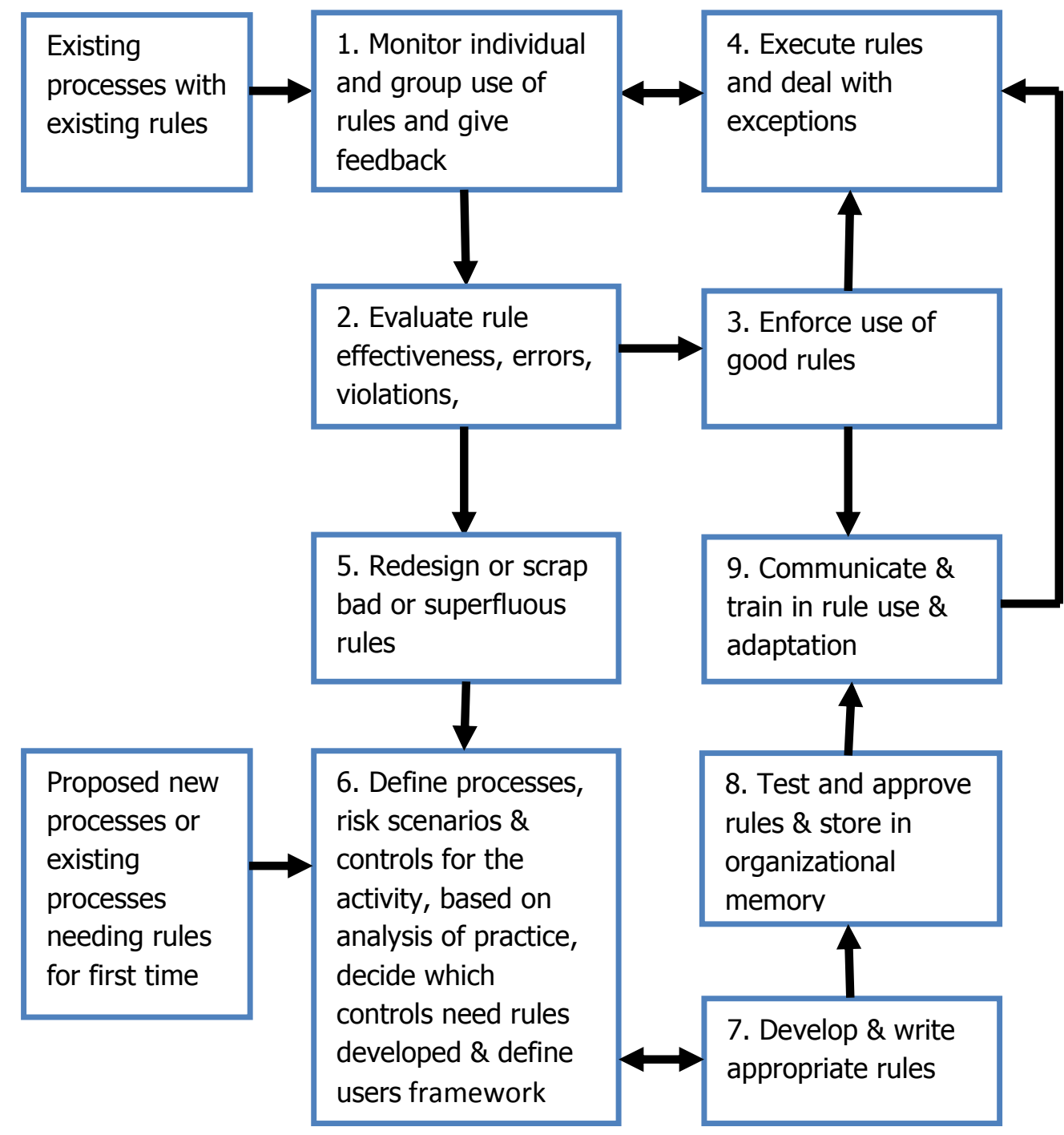

Figure 1. Generic Framework for Rule Management

\subsection{A Framework of Rule Management}

In order to analyze the effect of a large, complex rule set on the behavior of managers and companies, we need a framework showing the steps in the process of rule development, use, enforcement, and revision. We set out in figure 1 the generic framework devised in our review of workplace rules (Hale et al 2012a and b), but 
which, we believe, is also applicable for regulatory rules. What drives good workplace rule management is an active process of monitoring rule use (boxes 1-4). This demands evaluation of rule compliance, accidental violation, and deliberate violation. In cases of non-compliance, managers must assess if the reasons for noncompliance lie with the quality of the rules or the characteristics and motivation of those who should have followed the rule. Active rule monitoring also keeps the rule in the forefront of the minds of the rule-follower, the rule-maker and the supervisor. Depending on the result of the evaluation, the next step is either reinforcement of the rule or redesign of the rule. Box 5 starts a redesign process that may lead to a fundamental reconsideration of how the hazard will be best controlled through new formal rules as well as through redesigned work equipment, processes, work methods, or workplaces. Boxes 7-9 cover the processes of rule development, testing, approval, promulgation, communication, and training.

The review shows that the involvement of the rule-users, particularly in boxes 2 and 5-8, is important to good rule management in all cases, but the more so the more professional the rule-users are (e.g. doctors in hospitals, pilots of aircraft and maintenance fitters in high technology industries), it is especially important to consult them. Professionals are accustomed to devising their own routines for coping with the range of eventualities they meet and are more resistant to having rules and regulations imposed upon them. They usually regard such imposed rules as over-simplifications, written by people with only superficial knowledge of the complexity of reality and undervaluing the professionals' long years of "apprenticeship" and experience (McCarthy et al 1998, Grote et al 2009, Otsukaa et al 2010). However, even in much simpler tasks, outsider regulators tend to underestimate the complexity and diversity of the tasks, so involvement of the rule followers is needed also there.

If we now consider what happens to this generic process when we suppose that a distant, largely nonparticipative regulator imposes a large set of rules that are predominantly action rules, that cover a range of different activities, and that impact a wide range of people in the company, we arrive at figure 2 . We have kept the numbering of the boxes the same to facilitate the comparison with figure 1, but the order in which they are addressed changes, as we indicate below. We can use this framework to locate the issues set out in sections $1-3$.

The loss of boxes 2 and 5 and the presence of only a dotted line (representing a link that may or may not be present) between the monitoring function (box 1 ) and the adaptation process of the external regulations (boxes 6-8) indicates that externally imposed rules weaken or even remove the central motor of rule adaptation and improvement in the rule-management process of a company. This undermines the sense of ownership of risk management and results in token compliance with the letter and not the spirit of the law. No longer can organizations themselves modify, let alone scrap and replace, an action rule that does not fit their circumstances. They are bound to follow it, however impracticable or irrelevant it may appear to them. The only recourse is to use any remaining freedom of choice to find another implementation or translation (box 8) that is more appropriate and still acceptable to the enforcer. Only in the longer term can more fundamental changes be made through lobbying or on the initiative of the regulator. There will be uncertainty about when-or whether at all-such lobbying will succeed. If external rules are phrased as goals, outcomes, or riskmanagement process rules, the task of translation and adaptation remains inside the company and can still power the motor of rule management.

Working through figure 2, there is also a shift in where the company begins on the rule-management process. Instead of starting with the monitoring and optimization of rules at the "sharp end" of production, managers begin by asking which of their company's processes and activities are covered by external regulations. This turns their eyes outwards to the regulator instead of inwards to what would be sensible rules for the company and what rules are working well now or need modifying. This weakens the innovative spirit of the company.

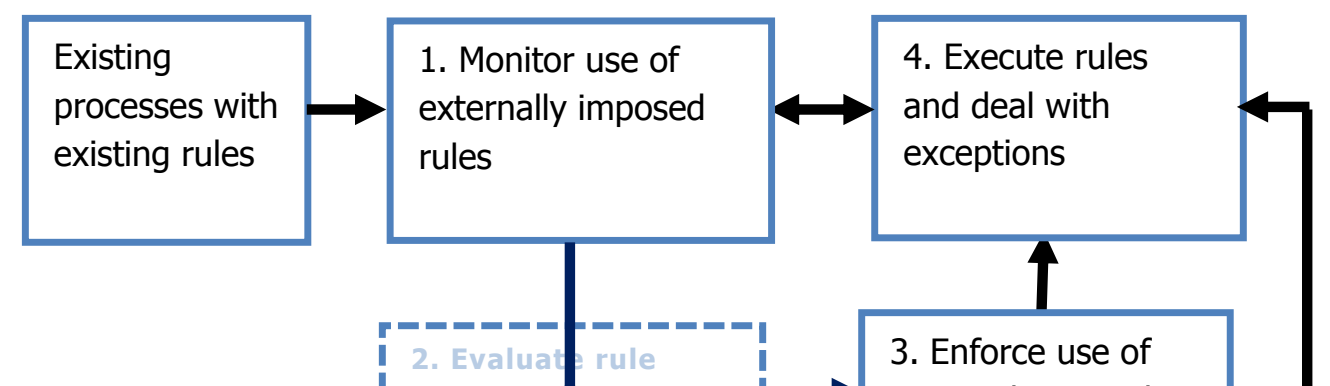


Figure 2: Generic Framework focused on External Regulations

The focus for the development of rules in boxes 6 and 7 now lies outside the company with the regulator, who is not so well placed as the company to know the best risk-control methods and to keep up with new developments. The regulations are therefore inclined to be sub-optimal and not to take account of the concerns of the company for balancing risk control with the need for competitiveness and avoidance of barriers to expansion. In dealing with the remainder of its task under boxes 6 and 7, the company has to face a jungle of existing, likely sub-optimal, detailed regulations, whose complexity and wording may confuse even the inspectors from the enforcement agencies (De Gelder 1997). The more the regulations are phrased as action rules, the more they will be cluttered with articles giving exemptions or dealing with special circumstances requiring exceptions to the normal regulation. To interpret such regulations, companies often turn to inspectors and enforcers or to consultants to tell them what to do.

One might argue that it would ease the difficulties of making the inventory of hazards, searching for regulations, and translating rules into organizational practices (boxes 6,7 , and particularly 8 ) if there were a good liaison between the companies and the regulators or inspectors so that practicable translations of the regulations could be agreed upon in a dialogue. This would give companies the certainty they desire that they are complying with the rules and need not fear an inspector's visit. Such collaboration calls for a high level of trust and strong professional relationships between regulators and regulated. Perhaps only with large companies with professional safety staff is there a level of equality and trust necessary for a professional debate on alternatives. However, this level of trust can allow firms to capture the regulator for their own devices and may be harmful to competition: large firms will seek to win exceptions to rules instead of changing bad rules and may even prefer that onerous rules stay in place, knowing that those rules will apply to their 
competitors. Trust may thus be a double-edged sword. Small businesses tend to regard inspectors warily and are not inclined to ask them into their organizations for discussion of this sort at all.

The legal language and complexity of the regulations means that the consultants or employees who carry out the hazard assessment, discovery of regulations, and translation of regulations into practices (boxes 6-8) must have legal training. However, lawyers are unlikely to be familiar with the technology, work methods, and hazards of the company's processes. Box 8 becomes crucial as the interface between the law and lawyers on one hand and the workplace and the practitioners of technical processes on the other hand. To find practicable and effective translations of the regulations, the technologically trained managers should dominate the lawyers. However, it is the lawyers who tend to dominate the practitioners when there are extensive and complex regulations to be implemented.

At the sharp end of rule use and enforcement (boxes 1, 3, 4, and 9), there are a number of factors relating to a mass of externally imposed regulations that discourage compliance, except as window dressing when an inspector or other enforcer is present. If those who will use the rules are not involved in deciding on, approving, and monitoring the rules and their use, it is likely that they will consider those rules "not invented here" and not adhere to them. If rules are seen as impracticable, both operators and immediate supervisors will collude in bending or even breaking rules and a company culture of non-compliance will develop. Studies show that managers are just as likely to breach rules as operators (Martin 2001).

When faced with a large and complex set of rules, managers, especially of small businesses, tend not to bother to find and learn about the rules (box 6) (Olson 1999), but rather to assume that the rules will match their own common sense and expertise (Fairman \& Yapp 2005). Managers thus rely on their own expertise as their basis for deciding how to control hazards. As a consequence, they think they are already complying with the regulations (Njaa \& Fjelltun 2010), which strengthens their belief that they need not seek out and study the regulations nor fear inspections. This fuels a deeply reactive response to rules, which may be called into question only when an inspector calls and points out non-compliance. What follows is a process of negotiation between inspector and company (Fairman \& Yapp, op. cit.), and the outcome of that negotiation is taken by the company to be the proper interpretation of the regulations (at least until another inspector calls). This reactive approach is particularly found in small businesses operating under abstractly phrased rules or under rules that are hard to discover.

We began our paper by noting that American businesses must now comply with 165,000 pages of federal regulations. Although the sheer number of regulations is problematic, it is the style and content of those rules that lies at the heart of the problem of regulatory overload. This determines the sense of ownership of the rules, their comprehensibility, as well as the degree of technical competence necessary to understand and implement them, and, ultimately, the likelihood that companies will accept and comply with the rules (Majumbar \& Marcus 2001). The need for clarity, explicitness, and enforceability of rules, which drives rules to become ever more action-based and restrictive, must be balanced against the need for freedom of decision and discretion to devise optimal solutions and cope with the diversity of reality and with exceptions to rules.

\section{Remedies}

Having located the different criticisms of the regulatory burden within our framework of the rule management process, we conclude with a section in which we draw on this framework to sketch options for tackling regulatory overload. While we of course recognize that our analysis is far from comprehensive, we believe that we make important suggestions about how to begin to reduce the regulatory burden that is weighing down economic growth. This section is particularly directed at the USA, and other countries where the style of regulation tends towards the detailed action/state rules. We start with the place that the regulator normally begins, namely our box 6 , the decision whether to regulate and if so how. This decision is often based on indications that existing regulation is not working adequately or at all. 


\subsection{Determining the need for regulations (box 6)}

Those opposed to the regulatory burden have started their opposition by questioning whether regulation is needed at all, whether it is the best and most efficient way to control risk or whether there are alternatives that would better control risk (Jones \& Graf 2001, Moran 2002). An answer to such questions depends on agreement on how to measure costs and benefits of regulation, no easy thing to achieve, especially with indirect costs and benefits. Moreover, there is a dearth of comparative studies of costs and benefits that look at how best to regulate and the relative costs and contributions to productivity of good and bad regulations. One of the few studies in this area examined the electrical utilities industry; this study found that wellformulated, flexible, outcome-based environmental regulations contributed positively to productivity while inflexible and action-based ones had a negative effect (Majumbar \& Marcus 2001). Although there are few comparative studies in this area, some economists and political scientists have offered checklists of qualitative questions regulators should address before deciding to embark on new regulations (Dudley 2010, Ruimschotel et al 1996, Royal Ministry of Government Administration 1994).

\subsection{Developing, testing, and approving appropriate regulations (boxes 7 and 8)}

We now consider what the "best" type of rules for given circumstances are and how the type of regulation affects the size and complexity of the regulatory rule book. Most literature on the regulatory burden is critical of "command and control" regulation and is particularly critical of action rules to govern the use of complex technologies. Most economists advocate "smart regulation" that takes advantage of the greater flexibility of outcome-based rules or risk-management process rules for mandated safety-management systems (Aalders \& Wilthagen 1997, Gunningham et al 1998, Hutter 1999, Ayres \& Braithwaite 1992, Ogus 2002) and safety-case regimes (Lavérie \& Flandrin 1991, Baldwin 1995, Saji 2003). These types of more flexible rules allow regulated companies to fill in the detail of the action rules themselves either as individual companies or collectively through their industry, trade, or professional associations (Chittenden et al 2002, Jones \& Graf 2001, Laurence 2005) This allows the government to scrap its own detailed action rules (Lord Robens 1972).

Many commentators have noted that flexible rules are suitable to govern the use of complex technologies operated by large companies (Laurence 2005, Majumbar \& Marcus 2001, Jones \& Graf 2001, Ogus 2002). However, in the Netherlands, the implementation of more flexible rules has been carried much further and is being tried in a wide range of industries. The Dutch government is funding the development by industry and professional bodies of catalogues of good risk-control practices relating to significant hazards in that industry or activity. These catalogues are subject to inspectorate approval but, once approved, will be used as the basis for the inspectorate's enforcement actions. Extant regulations will be repealed. Outcome-based and riskmanagement process regulations underpin these "outsourced" action rules (Baart \& Raaimakers 2010, Heijink $\&$ Oomens 2011). This does not reduce the number of detailed rules, but it does shift their origin to companies and industry groups and should increase companies' feelings of ownership of risk management.

A number of studies have looked at the use of risk-management process rules, which have been called "enforced self-regulation" in Europe and "management-level regulation" in the United States (Ogus \& Abbot 2002, Ayres \& Braithwaite 1992). These studies show almost uniformly that small businesses find such regulations difficult to understand and to implement. Thus small businesses often ignore the regulations or only implement what they consider to be "common sense" out of them (Janicak 1996, Fairman \& Yapp 2005, Loosemore \& Adonakis 2007). The cry from small businesses is usually that they want clear and simple rules to follow, because this saves them from investing a lot of time and resources into finding, understanding, and interpreting more flexible risk---management process rules. Unfortunately for safety regulations, this has typically meant that rules are phrased as action rules, which by their nature are more voluminous and complex to navigate. The dilemma for the regulation of small businesses is where to strike the compromise between specificity and flexibility, or indeed whether there is a suitable compromise to be found.

Large companies do have the resources, competence, and motivation to translate abstract goals or risk--management process rules into detailed rules. If a regulator changes the regulation from one that specifies 
concrete actions to one that prescribes outcomes or risk---management process systems, the regulator must also change its inspection strategy from inspecting on the basis of detailed external regulations to assessing safety-management systems and the detailed rules developed within such systems (Hale et al 2002). The latter may be a more difficult task for the regulator, as it cannot simply observe whether the externally prescribed procedures are being followed but must become deeply familiar with each company's unique safety protocols. Ashby and Diacon (1996) warn that vaguely defined goals and processes can breed legal loopholes and make enforcement and prosecution problematic.

Determining what regulations are most appropriate seems therefore to depend crucially on the size of the company and the complexity of its technology, which are often correlated. Large firms working with complex technologies prefer, and can cope with, flexible goals, outcome-based rules, and risk-management process rules, which give them the freedom to devise their own detailed solutions on the strength of their expertise and knowledge of their technology (Majumbar \& Marcus 2001). Small businesses operating less complex technologies, who may regard regulation at best as a necessary evil to be kept to the minimum, prefer clear, easily accessible rules, formulated in a concrete way (Australian Consumer Association 2005). Where outcome rules can be formulated in a concrete, measurable way, such rules may provide an optimum solution for both small and large companies. The dilemma is most acute where goals cannot be sensibly formulated in concrete terms.

Studies show regulators usually consult only large companies when developing regulations and neglect to consult smaller companies whose particular concerns remain unclear to regulators (Simeons 1986, Ogus 2002, Holman 2005). In Europe, this focus on large companies has led regulators to shift to risk-management process regulation, which tends to leave the small companies unsatisfied and seeking help to formulate the necessary action rules (Hovden \& Tinmannsvik 1990, Gunningham 2004, Gander 2001). The approach through riskmanagement process rules has not been attempted in the United States, with the possible exception of food safety regulation.

A potential compromise explored in some countries and industries is to have overarching outcome regulations underpinning risk---management process and action rules that are mandatory unless a company comes up with its own action rules and demonstrates to the regulator that its processes are at least equally effective in managing hazards. The Dutch experiment described above is a compromise along these lines but with elements outsourced to industry and professional associations rather than individual companies.

\subsection{Communicating and training in regulations (box 9)}

We have considered how the regulatory burden may be reduced by eliminating regulations that are not costeffective or by specifying outcomes or risk-management processes. The next best way to reduce the regulatory burden is to increase the accessibility of the regulation. More effective ways of finding, understanding, and interpreting relevant regulation are needed. Controlled studies have shown that training in the requirements of regulations increases compliance with regulations in small businesses and can even increase compliance with outcome-based or risk- management process regulations (Stokols et al 2001, Fairman \& Yapp 2005).

A number of authors point to the potential of information technology (IT) to help in this (Burman \& Daum 2009, Chittenden et al 2002, Hale et al 2010). They envision databases and expert systems that can be queried by the regulated organization to learn what applies to its processes and activities. However, we did not find examples in the literature studied of successful IT applications that solve the problem of ignorance of the law and its correct interpretation. The finding that practically no small businesses actively search for information on regulations with which they should comply suggests that simpler access to information about regulation may not improve knowledge of it. However, if such a regulation database were to be proposed, some national or industry leader must take charge of it, as developing an IT support system is not cheap and no small firm can bear its cost alone (Brito 2010). The alternatives for developing an IT support system are either that companies in industry, trade associations, or professional associations could coordinate to finance the project or that government could see it as part of its duty of informing the regulated of their obligations. 
If two or more agencies regulate the same activity of the company, those regulations may overlap and even conflict (Lord Robens 1972, de Gelder 1997, Burman \& Daum 2009, Aagaard 2011). Aagard shows that overlapping jurisdictions (he examines overlap between the Occupational Safety and Health Administration and the Environmental Protection Agency) need not cause problems if the overlap is explicitly managed by the two agencies. The agencies can resolve inconsistencies in regulations, systematize regulation and its implementation, and remove gaps both in rule making and in inspection practice by collaborating explicitly. Aagard also argues that it is an illusion to expect that all such boundaries between jurisdictions can be removed by amalgamating agencies. Only at the level of the organization do all of these jurisdictions come together. Agencies have their natural homes in areas of authority; boundaries can only be shifted but never eliminated. An explicit mandate to manage the boundaries can reduce conflict between agencies but this is harder when there are larger numbers of rules: the regulator is as human as the regulated and will have difficulty processing large and complex sets of information about rules and regulated entities.

\subsection{Enforcing the use of regulations (boxes $1 \& 3$ )}

We mentioned one of the main strategies adopted by small businesses in relation to compliance with a mass of regulations, namely to wait until the inspector comes and then to negotiate which regulations must be implemented (Fairman \& Yapp 2005). This process of negotiation effectively transfers the burden of boxes 6-9 to the inspectorate. Jurisdictions in Europe differ in whether they regard this as a legitimate role for the inspector or view it as a hidden subsidy of expert advice that companies should pay for from consultants or occupational safety and health services (Walters 2005).

Chittenden et al. (2002) propose that companies should be allowed to put the amount of a fine for non--compliance toward making their workplaces compliant. Such a provision would not differ much in principle from the British inspectorate's powers to order specific improvements in workplace safety to be made under the threat of a fine if the order is not followed. There is evidence that enforcement style influences how motivated company managers are to comply with regulation. Some studies argue that deterrent approaches, although still relevant, should not occupy center stage (Gunningham \& Sinclair 2002). Rather a more collaborative style of enforcement coupled with a mix of enforcement strategies is today more appropriate.

\subsection{Evaluating, redesigning, and scrapping regulations (boxes 2 and 5)}

In our review of the management of workplace rule management, we characterized the evaluation, redesign, and replacement of regulations (boxes 2 and 5 ) as the motor of good rule management. At the regulatory level, these activities are placed almost entirely outside the regulated organizations and instead with the regulatory agencies. However, that does not reduce the importance of this process. One reason for the proliferation of regulations is that effective mechanisms for reviewing and streamlining them are used infrequently. Such review can be forced by having "sunset provisions" limiting regulations' lifespans unless agencies renew them (Banks 2006, Australian Chamber of Commerce \& Industry 2005), or review can be compelled by Congress (Chittenden et al 2002). Agencies may also decide to review their own regulations periodically, as is currently being done by Environmental Protection Agency (2011).

Learning about and improving regulations will not occur unless some "learning agency" is designated as owner of that process (Koornneef \& Hale 1997). The government must clearly establish a "learning agency" to enable each regulatory agency to learn about what works, and what does not work, in its formal regulations. Learning about and improving regulations must be explicitly defined as a goal and the agency responsible for attaining that goal must be properly funded.

\section{Conclusions}

We have offered an analysis of rule use and management derived from our review of safety rules at the workplace and intra-organizational level. We have extrapolated from that analysis to consider the consequences for companies of having to comply with a large set of detailed regulations, especially when regulations are scattered across many different laws or enforced by multiple regulatory authorities. We have 
focused on analyzing the problem of regulation and its burdens and we have offered some suggestions of ways to reduce regulatory burdens. We conclude that, while the whole complex of detailed regulations does of itself impose a heavy burden of search and interpretation on companies, a potentially more serious problem is the strong forces pushing regulators to formulate their regulations at an action rule level. These forces lead to a proliferation of regulations and a jungle of exceptions and exemptions. To cope with such imposed action rules, companies focus on compliance rather than on managing risks. This turns compliance into a bureaucratic, legalistic paper game rather than a creative process of optimizing risk control and is likely to inhibit innovation.

We conclude that there is a large regulatory burden, particularly on small businesses. It is true that many regulations have benefits in excess of their costs, although these regulations may still be reformed to reduce costs or increase benefits. In a number of cases, information and incentives now exist that make these regulations ineffective or harmful and, after a proper analysis and review process, these regulations should be eliminated. Cost-benefit analysis can offer guidance on the advisability of introducing specific regulations by looking at the burden of compliance and its transactional costs in relation to the expected benefits of compliance.

To the extent that extant regulations are cost-effective, we have argued for a much closer attention to the style and content of proposed regulations. Companies that possess the motivation, resources, and competence to devise their own detailed risk-control solutions based on outcome and risk management process rules should be permitted to do so after regulators define appropriate outcomes. These changes would considerably reduce the size and complexity of regulations formulated at such levels. Companies know their own processes much better than outsider regulators, who frequently underestimate the complexity and diversity of tasks performed by the firm. Furthermore, when firms focus on problem---solving instead of compliance they are more likely to invest in experts who can find innovative solutions to problems. A shift to outcome-based and process rules would suit large companies and shift the role of enforcement agencies to monitoring outcomes or, with process rules, approval of solutions and enforcement of them. Many European countries have already moved in this direction. It is high time for the United States to consider following Europe's lead in this regard.

Small businesses are organized differently to large firms. Outcome-based regulation suits small businesses only when the outcomes to be achieved are easily measurable and the business has the competence to decide how to meet those goals. With many safety goals, it is difficult to define concrete outcomes, and a compromise must be struck between flexibility and clear, concrete rules that specify particular actions. Action rules can provide clarity and detailed guidance for those small businesses that do not have the staff or the time to devise their own action rules, provided that the rule sets are sufficiently small and knowable. As rule sets grow it is harder for firms to identify which rules apply to them. How, and whether, improved accessibility to the complex set of detailed rules can be achieved through innovative use of IT remains a question for study. Solutions can be sought in improving search access and by consolidating them into codes that are arranged not by regulatory jurisdiction but in terms of company processes. Industry and professional bodies can play a vital role in such translation roles. There is also a role for the regulatory agencies if they were to be given a mandate to do so. This could encompass collaboration with industry and professional bodies to help to develop such IT support.

When regulations are looked at piecemeal and their costs and benefits considered individually, the analyst loses sight of the cumulative effect of the whole set of regulations that apply to the same organization. Problems must have an owner if they are to be solved, and a too-large set of rules undermines companies' sense of ownership of the risks inherent in their processes. Regulatory agencies themselves, which have a strong interest in the amount and style of regulations they develop, are also part of the problem of regulatory overload. A body such as the Office of Information and Regulatory Affairs or the General Accountability Office in the USA may be better placed to take on a critical role, questioning the need for and style of regulations as well as bringing agencies together to resolve gaps and conflicts between their regulations. The various 
regulatory agencies should themselves coordinate across their jurisdiction boundaries. Each agency should have an office within it charged with learning how to improve regulations and optimize their burden on the regulated. The US Office of Advocacy of the Small Business Administration could also support this process by developing a small business standpoint on the style of regulation appropriate to small businesses.

\section{References}

Aagaard T. S. 2011 Regulatory overlap, overlapping legal fields, and statutory discontinuities. Virginia Environmental Law Journal, Vol. 29, No. 3,

Aalders, M. \& Wilthagen, T. 1997. Moving beyond command and control: reflexivity in the regulation of occupational safety and health. Law \& Policy 19(4) 415-443

Antonsen, S., Almklov, P. \& Fenstad, J. 2008. Reducing the Gap Between Procedures and Practice - Lessons from a Successful Safety Intervention," Safety Science Monitor 12(1): article 2

Ashby S.G. \& Diacon S. R. 1996. Motives for occupational risk management in large UK companies. Safety Science, 22, (1-3), 229-243

Australian Chamber of Commerce and Industry. 2005. Holding back the red tape avalanche: a regulatory reform agenda for Australia. Position Paper, Australian Chamber of Commerce and Industry, Barton, Australian Capital Territory.

Australian Consumers Association. 2005. Submission to Taskforce on reducing the regulatory burden on business. ACA, Marrickville, New South Wales, Australia

Ayres, I. \& Braithwaite, J. 1992. Responsive Regulation: Transcending the Deregulation Debate, New York: Oxford University Press.

Baart, P. \& Raaijmakers, T. 2010. Developments in the Field of Work and Health in the Netherlands in the Period of 1990-2010. Recommendation Paper for the Network of WHO Focal Points for Workers' Health, Amersfoort, the Netherlands.

Baldwin, R. 1995. Rules and Government: Non-Statutory Rules and Administrative Law, Oxford: Oxford University Press.

Banks, G. 2006. Reducing the regulatory burden: the way forward. Regulation Taskforce and Productivity Commission. Inaugural Public Lecture, Monash Centre for Regulatory Studies, Melbourne.

Baum, L. 1976. Implementation of Judicial Decisions, American Politics Research 4 (1): 86-114.

Beck, U. 1992. Risk Society: Towards a New Modernity. New Delhi: Sage Publications.

Brito, J. 2010. The Promise And Limits Of E-Rulemaking," research brief, Mercatus Center at George Mason University, Arlington VA, December 8, 2010, available at http://mercatus.org/sites/ default/files/publication/promise-and-limits-of-e-rulemaking 1.pdf).

Brockner, J., Higgins, E.T. \& Low, M.B. 2004. Regulatory focus theory and the entrepreneurial process. Journal of Business Venturing, 19, 203-220

Burman, W. \& Daum, R. 2009 Grinding to a Halt: The Effects of the Increasing Regulatory Burden on Research and Quality Improvement Efforts. Clinical Infectious Diseases; 49:328-35

CEN (Comité Européen de Normalisation). 1992. Safety of Machinery: Basic Concepts, General Principles for Design, part 1: Basic Terminology, Methodology and part 2: Technical Principles and Specifications, EN292-1 and EN292-2. Brussels: Comité Européen de Normalisation.

Crain N.V. \& Crain W.M. 2010. The Impact of Regulatory Costs on Small Firms Report to Small Business Administration, Office of Advocacy, Lafayette College, Easton, PA

Chittenden, F., Kauser S. \& Poutziouris P. 2002. Regulatory Burdens of Small Business: A Literature Review. Manchester Business School, Small Business Service.

Daugiradas, K. 2005. Evaluating Remand without Vacatur: A New Judicial Remedy for Defective Agency Rulemakings, New York University Law Review 80: 278-311.

Dekker, S.W.A. 2005. Ten Questions about Human Error: A New View of Human Factors and System Safety. Hillsdale, NJ: Lawrence Erlbaum Associates. 
Dudley, S.E. Fraas, A.G., \& Mannix, B.F. 2010. The Office of Management and Budget's Draft 2010 Report to Congress on the Benefits and Costs of Federal Regulations, research brief, Regulatory Studies Center at George Washington University, June.

Environmental Protection Agency. 2001. Improving on Regulation: Final Plan for Periodic Retrospective Reviews of Existing Regulations, (available at http://www.epa.gov/improving regulations/documents/eparetroreviewplan-aug2011.pdf).

Fairman, R. \& Yapp, C. (2005). Enforced Self- regulation, prescription, and conceptions of compliance within small businesses: The impact of enforcement. Law \& Policy, 27(4): 491-519.

Gander, P. 2001. Fatigue management in air traffic control: the New Zealand approach. Transportation Research Part F: Traffic Psychology and Behaviour, 4(1) 49-62

de Gelder, J. 1997. Conceptual modeling of building regulation knowledge. Artificial Intelligence in Engineering, 11, 273-284

Grote, G. 2006. Rules Management as Source for Loose Coupling in High-risk Systems Proceedings, Second Resilience Engineering Symposium, Juan les Pins, France, November 8-10

Grote, G., Weichbrodt, J.C., Günter, H., Zala-Mezö, E. \& Künzle, B. 2009. Coordination in high-risk organizations: The need for flexible routines, Cognition, Technology \& Work 11 (1): 17-27;

Gunningham N.A 2004. Best Practice Rail Safety Regulation. Working Paper 31, National Research Centre for Occupational Health and Safety Regulation, Regulatory Institutions Network, Australian National University. Canberra

Gunningham, N.A., Grabosky, P. \& Sinclair D. 1998. Smart regulation. Oxford, Oxford University Press

Gunningham N.A \& Johnstone R. 1999. Regulating workplace safety: systems and sanctions. Oxford University Press.

Gunningham N.A \& Sinclair D. 1998. Designing smart regulation in Smart Regulation: Designing Environmental Policy. In Gunningham, N.A., Grabosky, P. \& Sinclair D. 1998. Smart regulation. Oxford, Oxford University Press

Gunningham N.A \& Sinclair D. 2002. Leaders and Laggards: Next Generation Environmental Regulation, Greenleaf, UK,

Hale, A.R. \& Borys D. 2012a. Working to rule or working safely? Part 1: A state of the art review. Safety Science (in press)

Hale, A.R. \& Borys D. 2012b. Working to rule or working safely? Part 2: The management of safety rules and procedures. Safety Science (in press).

Hale, A.R., Borys D. \& Adams, M. 2011. Regulatory overload: a behavioral analysis of regulatory compliance. Working paper 11-47. Mercatus Center, George Mason University, Arlington, Virginia.

Hale, A.R., Goossens, L.H.J. \& van der Poel, I. 2002. Oil \& Gas Industry Regulation: From Detailed Technical Inspection to Assessment of Management Systems, in Changing Regulations: Controlling Risks in Society, (ed). Kirwan, B., Hale, A.R. \& Hopkins, A. Oxford: Pergamon, 79-108.

Hale, A.R., Guldenmund, F.W., van Loenhout, P.L.C.H. \& Oh, J.I.H. 2010. Evaluating Safety Management and Culture Interventions to Improve Safety: Effective Intervention Strategies, Safety Science 48 (8): 1026-35.

Hale, A.R. \& Swuste, P. 1998. Safety Rules: Procedural Freedom or Action Constraint. Safety Science 29 (3): 163-77

Heijink, J. \& Oomens, S. 2011. De werking van arbocatalogi: Evaluatie van het project arbocatalogi van de Stichting van de Arbeid [The working of the Working Conditions Catalogues of the Foundation for Work] (Project no. 340000768, Group ITS, Radboud University Nijmegen, Netherlands, February.

Holman. K.W. 2005. The regulatory flexibility act at 25: Is the law achieving its goal? Fordham Urban Law Journal 33, 1119-1137.

Hovden, J. \& Tinmannsvik, R.K. 1990. Internal Control: A Strategy for Occupational Safety and Health: Experiences from Norway, Journal of Occupational Accidents 12 (1-3): 21-30.

Howard P.K. 1994. The death of common sense: how law is suffocating America? Random House, London. 
Hutter, B. 1999. A reader in environmental law. Oxford, Oxford University Press

Janicak, C.A. 1996. Employers' knowledge of the hazard communication standard requirements and the perceived barriers to compliance. Journal of Safety Research, 27(4). 233-239.

Jentoft S. \& Mikalsen K.H. 2004. A vicious circle? The dynamics of rule-making in Norwegian fisheries. Marine Policy 28, 127-135

Jones, L. \& Graf, S. 2001 Canada's Regulatory Burden: How Many Regulations? At What Cost? The Fraser Institute, Vancouver, B.C. Canada.

Koornneef, F. \& Hale, A.R. 1997. Organisational feedback from accidents at work," in After the event: from accident to organisational learning, (ed.) Hale, A.R., Wilpert, B. \& Freitag, M. Oxford: Pergamon.

Lavérie, M \& Flandrin, R. 1991. Relations between the safety authority and the nuclear power plant operators. Nuclear Engineering and Design. 127, 215-218

Laurence, D. 2005. Safety rules and regulations on mine sites - The problem and a solution Journal of Safety Research 36, 39- 50

Jacques Leplat, J. 1998. About Implementation of Safety Rules, Safety Science 16(1): 189-204.

Löfstedt, R.E. 2011. Reclaiming health and safety for all: An independent review of health and safety legislation. Report to the Secretary of State for Work and Pensions. Command 8219. London. HM Stationery Office.

Loosemore M. \& Andonakis N. 2007. Barriers to implementing OHS reforms - The experiences of small subcontractors in the Australian Construction Industry, International Journal of Project Management 25, 579-588

Majumdar, S.K. \& Marcus A.A. (2000). Rules versus discretion: The productivity consequences of flexible regulation. Academy of Management Journal, 44(1): 170-179.

Martin, L. 2001. Bending the Rules or Fudging the Paperwork? Documenting Learning in SMEs. Journal of Workplace Learning 13 (5): 189-97.

McCarthy, J.C., Wright, P.C., Monk A.F. \& Watts, L.A. 1998. Concerns at Work: Designing Useful Procedures, Human-Computer Interaction 13 (4): 433-57;

Moran M. 2002. Understanding the regulatory state. British Journal of Political Science, 32, 391413

Njå, O. \& Fjelltun, F.H. 2010. Managers' attitudes towards safety measures in the commercial road transport sector. Safety Science 48, 1073-1080

Obama, Barack, "Toward a 21st---Century Regulatory System," The Wall Street Journal, January 18, 2011 (wsj.com/article/SB100014240527487033396604576088272112103698.html).

Ogus A. 2002 Comparing regulatory systems: institutions, processes and legal forms in industrialised countries working paper No. 35, Centre on Regulation and Competition, University of Manchester. Manchester, UK

Ogus, A. \& Abbot, C. 2002. Sanctions for pollution: do we have the right regime? Journal of Environmental Law 14(3) 283-298

Olson M. 1982. The Rise and Decline of Nations. New Haven, Connecticut: Yale University Press.

Olson, M. 1999. Agency rulemaking, political influences, regulation and industry compliance. The Journal of Law, Economics \& Organization, 15(3): 573-601.

Otsukaa, Y., Misawab, R., Noguchic, H. \& Yamaguchib, H. 2010. A Consideration for Using Workers' Heuristics to Improve Safety Rules Based on Relationships Between Creative Mental Sets and Rule-Violating Actions, Safety Science 48 (7): 878-84.

Reagan, Ronald. 1981. "Remarks Announcing the Establishment of the Presidential Task Force on Regulatory Relief" (January 22), available online at The American Presidency Project (http://www.presidency.ucsb.edu/ws/index.php?pid=43635).

Lord Robens, 1972. Report of the Committee on Safety and Health at Work 1970-1972 London: Her Majesty's Stationery Office.

Royal Ministry of Government Administration. 1994. To Regulate - Or Not: Checklist for use when deciding on instruments and new regulation, Oslo: Norway 
Ruimschotel, D, van Reenen, P \& Klaasen, H.M. 1996. De tafel van elf. (the table of eleven) Beleidsanalyse 3 4-13Saji, G. 2003. Safety goals in 'risk-informed, performance-based' regulation Reliability Engineering and System Safety 80, 163-172

Saji, G. 2003. Safety Goals in 'Risk-informed, Performance-based' Regulation, Reliability Engineering and System Safety 80 (2) 163-72.

Simeons, C. 1986. Health and safety regulations: a key issue for the board. Long Range Planning, 19(3), 86-92

Peltzman, S. 1976. Toward a More General Theory of Regulation, Journal of Law and Economics 19 (2): 211-40

Stigler, G.J. 1971 "The Theory of Economic Regulation," The Bell Journal of Economics and Management Science 2 (1): 3-21

Stokols, D, McMahan, S., Clitheroe Jr. H.C. \& Wells, M. 2001. Enhancing corporate compliance with worksite safety and health legislation. Journal of Safety Research 32, 441- 463

Walters, D. 2005. The challenge of change for strategies on health and safety at work in the $21^{\text {st }}$ century. Policy \& Practice in Health and Safety, 3(2) 3-20.

Weick, K.E. 1996. Drop Your Tools: An Allegory for Organizational Studies, Administrative Science Quarterly 41 (2): 301-13.

Lord Young, 2010. Common Sense, Common Safety: Report to the Prime Minister. London: Her Majesty's Stationery Office. 